\title{
Umesp/Psicologia 45 Anos... e 40 anos meus nesta instituição
}

\section{My 40 years dedicated to the Psychology of Methodist University}

Olímpia Rosa Noronha*

\begin{abstract}
Resumo
O texto em questão resgata a história da Psicologia na Universidade Metodista e lembra ainda a trajetória da autora nessa Instituição. Para tal, relembra dos anos iniciais do curso, o percurso do próprio curso e o prazer de ser professora e supervisora.
\end{abstract}

Palavras-chave: Psicologia; Universidade Metodista

\begin{abstract}
This paper rescues the history of Psychology at Methodist University and also reminds the trajectory of the author in the Institution. Therefore, she reminds recalls the beginning of the course, the course itself and the pleasure of being a teacher and supervisor.
\end{abstract}

Keywords: Psychology; Methodist University

Era uma vez... como se iniciam os contos de fadas, que também falam dos fados da vida, que pretendo começar este artigo ou palestra, para contar a minha história, aliás, a única que verdadeiramente apenas eu poderia contar! Nunca a real, na medida em que obrigatoriamente, qualquer história passa pelo subjetivo de quem a conta.

Naturalmente, essa história tem antecedentes que nos remetem a registrar aqui, o surgimento do primeiro curso de Psicologia no Brasil,

\footnotetext{
* Psicóloga; Psicanalista - Sociedade Brasileira Psicanálise SP; Mestre em Psicologia; Supervisora de Estágios em Psicologia Clínica - Universidade Metodista de São Paulo
} 
em 1958, funcionando na Faculdade de Filosofia, Ciências e Letras da USP-SP, sendo que a regulamentação para os cursos de formação de psicólogos só ocorreu em 27 de agosto de 1962, datando dessa época, a instituição da profissão de psicólogo. (RUBIANO, 2005)

E exatamente 11 anos depois da criação do primeiro curso de psicologia, começo a minha formação em Psicologia na USP; com certeza, nessa época, não tinha a menor ideia do que aconteceria com meu futuro profissional.

As datas, apesar de nos produzirem algumas confusões, são importantes para que possamos nos colocar no espectro histórico, e nos facilitar uma retomada do passado, sempre a partir de nosso presente. E exatamente 13 anos depois do início da Psicologia no Brasil, a Instituição Metodista de Ensino Superior (IMS) dava início ao seu curso de Psicologia, precisamente em 1971.

Quando começamos a pensar nas comemorações dos 45 anos da Psicologia na Metodista, não tivemos como não apelarmos para nossa memória, às vezes bastante deficitária, outras até mesmo traidora, na tentativa de resgatar não só a história do grupo, mas também as histórias individuais, neste caso em especial, a minha, que me remete há quarenta anos atrás!!!

Relembraria aqui o que meu professor da época da USP, César Ades (2004), escreveu: "O grupo representa mais do que o conjunto de oportunidades a partir das quais se concretizam as ações individuais, ele é a matriz na qual a individualidade se estrutura e na qual se desenvolvem as ações significativas da pessoa, efetuadas no espírito de pertencer e de participar" (p. 241).

Ainda Ades (op.cit.), comentando o livro de Ecléa Bosi (O tempo vivo da memória: ensaios de Psicologia Social, de 2003) refere-se a uma memória que não deve se trancar em si mesma, mas sim partilhar seus conteúdos àqueles que oferecem seus ouvidos, para ouvir uma história que se pretende contar. O que pretendo aqui, é lhes contar a história produto do entrelaçamento da minha trajetória com a do curso de Psicologia Metodista, ao que construí ao longo desses 40 anos de trabalho nesta instituição, com todos os vieses de minha percepção e distorções de minha memória.

A Psicologia na Metodista tinha apenas cinco anos quando fui acolhida por ela. Ainda estava ligada à USP, à Fundação Armando 
Álvares Penteado, Faculdade Ibero-Americana, nas quais exercia funções docentes. Como residia em São Paulo, no primeiro dia que vim ao IMS/São Bernardo do Campo, para ser entrevistada, indicada que havia sido por uma ex-professora da casa para substituí-la na docência, lembro-me que considerei grande a distância quilométrica entre os municípios (tal distância logo assumiu uma métrica afetiva, tornando-se muito menor). Mas alguma coisa me atraiu muito, ou melhor dizendo, usando uma linguagem psicanalítica, houve o estabelecimento de uma transferência positiva muito forte, que terminou por provocar que ao longo de uns bons anos, eu fosse me despedindo das outras instituições, e elegendo a Metodista como minha escolhida.

E neste momento, como já o fiz em outros, pergunto-me como iniciei esta carreira de docente universitária (visto ter tido sempre uma forte inclinação para a clínica), mesmo sabendo-me tendo feito o curso de formação de professores, antigamente conhecido como Normal, além da licenciatura durante a formação em Psicologia na USP. Ou seja, teria muitos motivos para aderir à carreira docente. Assim que me formei, fui convidada a dar aula na FAAP (Fundação Armando Álvares Penteado), e com toda minha inexperiência, me vi à frente de uma sala de 80 alunos de um curso de Comunicação. $\mathrm{O}$ que fazer? Por mais que minha ex-professora Maria Margarida de Carvalho (a quem tenho uma gratidão extrema) tivesse me passado o plano de ensino e pedagógico, me dado instruções sobre o que fazer, aquele momento foi único; hoje, ao me lembrar dele, ainda sinto arrepios de medo, ao mesmo tempo em que vejo que me saí razoavelmente bem dele, não apenas segundo meu próprio referencial, mas também pela direção dessa renomada instituição, na qual trabalhei por vários anos. Conto essa história aqui, porque me serviu de estágio preparatório para a função docente que viria a exercer nas demais faculdades, incluindo a Metodista.

Devo deixar registrado aqui, que ao atender a essa indicação de minha colega, não estava num momento profissional em que eu estivesse "inativa", ou aguardando ofertas profissionais; bem pelo contrário, como especificarei abaixo; dispus-me a conhecer a Metodista, reconheço hoje, movida por um furor de crescimento e voracidade em me desenvolver, que precisaram ser trabalhadas 
ao longo dos meus muitos anos de análise pessoal. Nessa época, ainda estava com a USP, FAAP, Ibero-Americana, fazendo pós em Psicologia Clínica na USP, pós em Educação na Federal de São Carlos, e pós em Psicologia Clínica na PUCSP, além de trabalhar num consultório psiquiátrico e na clínica da Prof ${ }^{-a}$ Maria Margarida de Carvalho. Hoje me dou conta da loucura em que me vi envolvida, e também do preço que tive que pagar por toda essa necessidade/ urgência em "dar certo", "ter sucesso". Este percurso de minha vida não é conhecido de muitas pessoas, mas, dispus-me agora, a escrever sobre.

Então, cheguei à Metodista, fui entrevistada, curriculum avaliado, e fui aceita para fazer parte do corpo docente do curso de Psicologia, que estava formando sua primeira turma, fato esse que muito me atraiu: ajudar talvez, a construir essa história! Quê ousadia! Mas algo funcionou, porque depois de mais de 40 anos, aqui estou, cada vez mais inserida nesse projeto.

Comecei dando aulas, o que fiz até recentemente; no final de 1976, Prof Johannes Berkers, chefe do Setor de Psicologia Aplicada, me entrevistou para que eu pudesse assumir as supervisões de Psicologia Clínica; a partir de então, passei a exercer as duas funções: professora e supervisora.

Algumas vezes fui convidada a assumir cargos de chefia, mas declinei dos convites, uma vez que reconheço em mim, uma total inabilidade, incompetência para atividades tão importantes e difíceis (pelo menos para mim) de serem praticadas.

Ao longo desse percurso, foi ficando claro para mim, que meu objetivo não era fazer "carreira" docente, apesar de gostar muito da docência. Resolvi restringir minhas atividades profissionais apenas à Metodista e ao meu consultório particular, e tomando uma decisão importantíssima: fazer formação em Psicanálise na Sociedade Brasileira de Psicanálise de São Paulo.

Neste momento em que estamos comemorando 45 anos da Psicologia da Universidade Metodista de SP, e ao pensar no que poderia escrever aqui, vi-me tomada de dois sentimentos igualmente intensos: AMOR e PAIXÃO.

Refiro-me ao amor e paixão por aprender e ensinar, que me acompanham há bem mais de 40 anos, e posso afirmar que foi isso, 
fundamentalmente, que me manteve aqui por todo esse tempo. Devo salientar ainda, que do lado da Metodista Instituição, também não é fácil manter um professor por todo esse tempo; não creio ter dado muito trabalho aos meus diretores/coordenadores/colegas, assim como o reverso é verdadeiro.

Amor e paixão são essenciais para qualquer objetivo a que se proponha na vida, mas entendo que o que permeou e permeia meu trabalho de ensinar/aprender, sempre tem sido uma luta, que me colocou em constante movimento. Não entendo o "professorar"/ ensinar, sem o aprender. E sempre foi um desafio tentar apaixonar nossos alunos, por essa beleza que é o aprender! Com certeza, perdi muitas dessas lutas, e não atribuo tais perdas às características dos alunos, mas com certeza, àquilo que eu ainda não havia aprendido, e é grande a probabilidade de não tê-lo conseguido hoje. Até mesmo para amenizar minhas cobranças e angústias, ouso pensar na questão de responsabilidade da dupla formada por aluno/ supervisionando-professor/supervisor, e não que isso tenha sido instituído nessas minhas análises, apenas para meu alívio! Isso faz parte do que tenho aprendido graças aos meus estudos aliados a minha experiência. Lembraria aqui, um psicanalista não tão famoso quanto Freud, mas igualmente importante: Bion (1962), que entre muitas de suas produções, ressalto seu livro "Aprender com a experiência" ${ }^{1}$. Não entrarei aqui em detalhes teóricos, mas me aterei ao título: se isso não acontece na nossa vida, então, para que estamos vivendo? De que servem as experiências que temos, para que tê-las, se não as praticamos? Rezende (1994) "bioniza" uma frase de Kant: "a experiência sem aprendizagem é cega, e a aprendizagem sem experiência é vazia”, que me parece muito pertinente pensarmos nela, não apenas na formação de analistas, que é o objetivo do autor supracitado, em seu texto "Bion formador de analistas", mas também na nossa formação de professores/supervisores, naquilo que vai além da discussão didático-pedagógica.

Salvitti (2013) defende que a tradução para o Português do livro Learning from experience seria mais adequada se fosse "Aprendendo a partir da experiência", ou da experiência, além de enfatizar que "learn" seria melhor entendido como "descobrir", e não ficar restrito à conotação pedagógica do "aprender". 
Como me tornei professora? Como me tornei supervisora? Como me tornei analista? No início deste texto descrevi apenas alguns dados referentes ao como fui assumindo as funções de professora e supervisora. No entanto, isso fica muito distante de responder às perguntas acima. Relatei onde estudei, como fui me inserindo profissionalmente nas instituições de ensino, como fui me construindo como a profissional que sou hoje. Mas, nada disso atende ao processo envolvido nesse "como" das questões colocadas no início deste parágrafo. Nem me proponho a discorrer aqui sobre todo esse aprendizado e transformação, que caberia em outro trabalho; apenas aproveito para levantar incitações a um pensar, que não seja simplesmente cognitivo, voltado para resolução de problemas, mas que inclua uma capacidade realística de se encontrar boas saídas para nossas frustrações, relacionando conhecimento, formação do psiquismo e aquisição da capacidade simbólica (BION, 1994).

É importante se comemorar certas datas, pois é uma oportunidade de se olhar para trás, e pensarmos, bionianamente ou não, nesse tempo, nas coisas conseguidas, nas não conseguidas, nos sucessos e fracassos, percebendo como todos foram importantes para se chegar onde estamos hoje. Faria um elo do que Bion escreveu em "Aprender com a experiência" (op.cit.), com a posição de Ecléa Bosi (2003), ao afirmar que uma história de vida não existe "para ser arquivada ou guardada numa gaveta como coisa"(p.69), devendo ser usada para provocar transformações. Assim estou vendo estas nossas comemorações: uma forma de publicar nossa história e de transformarmos a nós mesmos, individual e institucionalmente.

Quando iniciei meu trabalho na Metodista, a Psicologia entrava no seu sexto ano de vida, como uma criança que ainda precisava de muitos cuidados (não que hoje não continue precisando); ela conseguiu alguns desmames básicos, controlou seus esfíncteres, teve a troca de sua dentição, passou pela adolescência, vivendo suas crises próprias, e vem tentando dar conta dos desafios adultos. O que ela diria se se deitasse num divã? Culpabilizaria seus pais, reclamaria dos azares que os sistemas político-econômicos provocaram, das pessoas que por ela passaram e que não souberam cuidar dela com carinho, dignidade, que não teriam investido tudo o que deveriam ou poderiam? E o que ela diria de mim? 
Pode ser que ela estivesse ainda num momento em que não conseguisse assumir suas próprias responsabilidades, não tivesse atingido a fase genital, tão discutida em Freud. É possível que apresentasse algumas fixações orais, anais e principalmente fálicas, que até explicassem momentos mais fortemente neuróticos em sua história, e por que não, alguns episódios autísticos, lembrando o que Frances Tustin (1984) analisanda de Bion, fala em seu livro "Barreiras autistas em pacientes neuróticos": núcleos encapsulados que protegeriam o indivíduo de uma depressão profunda. O grande perigo disso seria se a Psicologia/UMESP tivesse "recorrido" a tais núcleos para evitar momentos difíceis depressivos, desconfiando de uma estrutura interna que lhe possibilitasse enfrentar essas dificuldades. Fato é que passaria boa parte dessa "análise fictícia" contando de sua "infância", adolescência, lembrando-se das várias "casas" que teve, das várias mudanças e das inseguranças que lhe traziam: quando ela se acostumava num lugar, e aqui ela se lembra de quando o curso e clínica aconteciam no prédio da Faculdade de Teologia (prédio Alfa), casa mais antiga, mas muito aconchegante, com uma vista bucólica para um bosque a sua frente, que hoje não existe mais, tendo dado lugar a um estacionamento, com alguns exemplares de árvores posteriormente plantadas. Ela se lamenta, num momento mais egoísta e autocentrado, de não ter tido uma casa só dela, não entendendo esse ter que dividir espaços com outras faculdades; seu analista até chegou a lhe dizer que esse compartilhamento fazia parte de um amadurecimento, mas foi difícil livrar-se de um olhar mais umbilical! Ainda nessa fase na análise, houve necessidade do analista chamá-la para a realidade: houve um tempo em que a Psicologia de fato, teve uma casa, em dimensões maiores que as do prédio Alfa, e que também acolheu toda a sua graduação e clínica! Essa mudança foi em 2002, quando saiu do campus Rudge Ramos para apossar-se de um prédio novo no Planalto. Psicologia chora, ao se dar conta de sua reclamação quase que infundada, tendo se esquecido que isso aconteceu de fato; lembra-se no entanto, que essa mudança foi muito dolorida, porque implicava em se afastar de seus amigos de "alma", como Comunicação, Letras, Filosofia. Mas, passados uns instantes, ela reconhece o lado positivo de tal mudança, e que o "Planalto" era 
muito bom (apesar das dificuldades também presentes), principalmente porque todos seus cinco anos estavam juntos, unidos numa só casa. Parecia que nesse momento analítico, ela estava sendo mobilizada a pensar num movimento de crescimento, assumindo o que teve de bom e mal. No entanto, tal estado não se mantém, pois logo é abatida por uma depressão, ao se lembrar que isso durou pouco tempo: em 2010 traz uma experiência de psicotização, ao ter que enfrentar a separação de dois núcleos importantíssimos: um de formação mais pedagógica propriamente dita, e outro, envolvendo a prática clínica. Reclama que se sentiu esfacelada, e que novamente sentiu-se à deriva, sem ter sido respeitada em seus pensamentos/ sentimentos. Chorou muito, praguejou, atacou seu analista, num movimento transferencial fortemente negativo, ameaçou inclusive interromper a análise. Isso tudo foi bem contido na análise, e seu trabalho pode seguir adiante, sendo-lhe mostrado que faz parte da vida adulta madura, aceitação de acontecimentos que por vezes, fogem a nossa alçada, sem no entanto, que isso se configure numa posição passiva de simplesmente aceitar tudo. Psicologia conseguiu digerir algumas dessas coisas, mas ainda, em algumas sessões, esse assunto aparece com força total!

Em 1998, com a passagem a Universidade Metodista de São Paulo, a Psicologia passa a integrar a Faculdade de Ciências da Saúde, e esse se constitui num outro momento crítico de sua análise no divã, pois com isso, ela deixou de fazer parte das Humanidades; no divã, lamentou profundamente tal decisão. A Psicologia não se sentiu ouvida, nem considerada por seus "pais e mães": colocaramna num lugar que lhe causou uma crise de identidade. Afinal, pelo fato de ter algumas disciplinas como Estatística, não a tornam Exata, da mesma forma que por ter disciplinas como Biologia e Fisiologia, não a tornam uma ciência biológica.

Isso tomou um grande número de sessões, não apenas num movimento apenas "reclamatório", mas com nuances mais amadurecidas, na tentativa de entender o que teria se passado; no entanto, foi difícil deixar de sentir-se inconformada e desrespeitada naquilo que pensa. Nesse momento de culpabilizar o outro, suas flechas me atingiram, na medida em que na época, não fui continente ao seu desespero, nem compreensiva com usas dores. É possível que esse 
material tenha precisado ficar "encapsulado" para que pudesse "continuar sua vida", evitando paralisias mentais desconstrutivas e impeditivas de um crescimento. Devo deixar marcado aqui, que Dra Marília Martins Vizzotto representou nessa época, o pensamento de que a Psicologia não deveria sair das Humanas. No entanto, tal movimento vinha se anunciando desde que o SUS (Sistema Único de Saúde) foi criado, em consequência do que a Psicologia passa a ser reconhecida, pelos Ministérios da Educação e da Saúde, como uma disciplina da área da Saúde (e não mais somente das Ciências Humanas).

Tentei com esses fragmentos de um estudo de caso refletir momentos angustiantes, envolvendo pulsões de vida e de morte, que a Psicologia/Metodista passou nesses 45 anos de existência. Devo dizer que sua análise no divã continua, tentando dar contar dos núcleos neuróticos/psicóticos que surgem na vida psíquica de um ser humano, e que neste exercício de livre-pensar a que me dei o direito, antropormofizei uma entidade educacional, colocando-a num "divã", onde espero que ela se mantenha por muito mais tempo!

E eu? Continuo com minhas análises, meus questionamentos; cada vez mais inserida num trabalho que me gratifica enormemente, que hoje está mais configurado ao exercício da função de supervisionar os estagiários que iniciam suas incursões no trabalho clínico.

Em 2002, participando de um Encontro de Clínica-Escola, apresentei o trabalho: "Supervisão como parte da formação do psicólogo: é possível uma aprendizagem?", a partir do qual Prof ${ }^{a}$ Elaine de Oliveira Lima, diretora da Faculdade de Psicologia e Fonoaudiologia apoiou o projeto de se criar o Fórum de Supervisores, que se mantém até hoje. Nesse trabalho, enfatizei a necessidade de haver um processo de formação de supervisor, em contraposição à ideia de que seria automática a passagem do "ser professor", para o "ser supervisor".

Kuznetzoff e Groisman (1981) mostraram que a supervisão, entre a opção educacional e a terapêutica, ficou numa zona intermediária, ambígua, num território que é de todos e não é de ninguém. Além disso, deve-se considerar que, como escreveu Solnit (1970), a supervisão é a principal atividade de ensino, enquanto atividade que permite uma aprendizagem mais visceral. 
Esse campo de intersecção entre educação e prática profissional pode ser entendido de uma forma muito ingênua, por exemplo, ao se pensar que nos estágios com objetivos de formar psicólogos clínicos, tenhamos simplesmente que transformar os conhecimentos oferecidos ao aluno em sua graduação, em processos técnicos aplicados à prática profissional. Entendo que a atividade do profissional psicólogo implica em algo mais do que uma "aplicação" do conhecimento teórico básico à experiência. Como exemplo desse "algo mais" acrescentaria, além da teoria, técnica, prática, uma linha diretriz que perpassa todos esses itens: refiro-me às questões éticas, que nos colocam diante de dificuldades aparentemente crescentes em nossa experiência com os alunos e/ou estagiários, e que em vários momentos, me leva a questionar até que ponto nós, supervisores/ professores, podemos desenvolver/criar/produzir um pensamento, uma prática eticamente responsável.

O trabalho no Fórum de Supervisores frequentemente nos apresenta situações que, se não tivermos uma capacidade de acreditar que podemos ir além, corremos sérios riscos de sairmos da posição de educadores, enquanto praticantes de uma Educação maior, ficando submetidos então, a replicadores de instruções. Parafrasearia uma declaração de John F. Kennedy, em seu discurso de posse na presidência dos Estados Unidos ${ }^{2}$, em 1961: não perguntem o que a educação pode fazer por vocês - mas, o que vocês podem fazer por ela! O sentido político da frase original não é meu objetivo aqui, mas sim fazer um paralelo com a educação: precisamos nos ater ao que NÓS podemos fazer pela Educação, pelos nossos alunos, pelos nossos estagiários, pelas pessoas que cruzaram nossas vidas ( e nós, as delas), esperando menos deles e dela (Educação), implicando-nos cada vez mais, neste difícil, mas não impossível, ofício de ensinar.

E terminaria este texto dizendo que, neste ofício de ensinar, aprendi muito!

2 A frase em questão é: “(...) não perguntem o que seu país pode fazer por vocês - mas, o que vocês podem fazer pelo seu país." 


\section{Referências}

ADES, C. A memória partilhada. Resenha de: Bosi, Ecléa. O Tempo Vivo da Memória: Ensaios de Psicologia Social. Psicologia USP, 2004, v.15, n.3, p.233-244, 2003.

BION, W. R. Estudos psicanalíticos revisados. Tradução: Wellington M. de Melo Dantas. 3. ed. Rio de Janeiro: Imago, 1994.

BION, W.R. Aprender com a experiência. Tradução Paulo Dias Corrêa. Rio de Janeiro: Imago, 1991. (original de 1962).

BOSI, E. O tempo vivo da memória: ensaios de psicologia social. São Paulo: Atelê Editorial, 2003.

KUZNETZOFF, J.C. ; GROISMAN, M. - Supervisão e co-supervisão grupal. Ensino, terapia e aprendizagem em um setor institucional. J. Bras. Psiq. n.30, p. 71-84, 1981.

RUBIANO, M.R.B. Apresentando a Sociedade Brasileira de Psicologia. In: MELOSILVA, L.L; SANTOS, M.A; SIMON, C.P. (Orgs). Formação em Psicologia: Serviços escolas em debate. São Paulo: Vetor, 2005. p. 31-54.

SALVITTI, A. Experiência em grupo: notas sobre o estilo de Bion, transmissão e método de leitura. J. psicanal. São Paulo, v.46, n.85, p.159-164, 2013.

SOLNIT, A. - Learning from psychoanlytic supervision. The International Journal of Psychoanalysis, n. 51, p. 359-362, 1970.

Contato do autor:

Olímpia Noronha:

Olímpia.noronha@metodista.br

Recebido em 15/01/2016

Aceito em: 05/03/2016 